DOI 10.31489/2020No2/78-86

UDC $621.577+697.1$

\title{
THE HEAT PUMP SYSTEM FOR VENTILATION AND AIR CONDITIONING INSIDE THE PRODUCTION AREA WITH AN EXCESSIVE INTERNAL MOISTURE GENERATION
}

\author{
Bezrodny M.K., Misiura T.O. \\ National Technical University of Ukraine "Igor Sikorsky Kyiv Polytechnic Institute", Kyiv, Ukraine, \\ Sconosciuto.T@gmail.com
}

\begin{abstract}
The paper studies application feasibility and energy efficiency of the ventilation and air conditioning heat pump system for maintaining comfort conditions inside the production area with an excessive internal moisture generation during the warm season. In this regard, a thermodynamic analysis of a heat pump system with a partial exhaust air recirculation and a variable ratio of fresh outside air was carried out. Numerical analysis was then done to estimate the influence of changes in the environment temperature and relative humidity and the characteristics of the ventilation and air conditioning object on the system parameters. This allowed to determine potential capabilities of this system to maintain comfortable conditions in the production area. It was also shown that the required additional cooling of the supply air at the entrance to the premise for air conditioning demands can be determined by a simple coefficient and its calculation method is provided in the article. The heat pump system of temperature and humidity maintenance has the highest energy efficiency in the zone of relatively low environment temperatures and largely depends on the relative humidity of the outside air. This suggests that the studied system is suitable for application in countries with temperate continental climate.
\end{abstract}

Keywords: heat pump system, ventilation, air conditioning, refrigeration efficiency, recirculation, comfortable conditions, production area, temperate continental climate.

\section{Introduction}

The trend of increasing energy resources costs for final consumers makes it vital and primary to constantly enhance the efficiency of equipment and to find new ways and methods of utilising low-potential energy in order to replace traditional heat sources, which involve the combustion process of expensive and limited fossil fuels [1].

Nowadays systems with heat pumps (HP) are considered to be an alternative energy source for heat supply. They are widely used for ventilation and air conditioning of various objects, among which predominant are those that require maintenance of not only temperature but also humidity conditions indoors due to excessive internal moisture generation [2]. Examples of such objects may be shopping centres, sports facilities as well as production, storage and sorting facilities with required specific technological and comfort conditions. Removal of excess moisture from such premises is normally done with the exhaust ventilation. Maintenance of set parameters (temperature and humidity) of air inside a premise during the warm season can be achieved by supply air pre-treatment in a heat pump system (HPS) [3]. The implementation of HP in such systems has some features, since the dried air after the HP evaporator needs to be heated up to a set temperature at the entrance to a premise, which can be organised in different ways. One of them is by mixing of one air flow cooled down in the HP evaporator with another air flow heated up in the HP condenser [4]. The energy efficiency of such HPS increases due to the partial recirculation of the exhaust air and thus due to the partial utilisation of the cold produced by this HPS. However, the analysis performed in [4] concerns the system operation in terms of premise ventilation only without external and internal entrance of heat, i.e. in conditions without air conditioning.

In this regard, the authors propose and analyse the basic ventilation and air conditioning HPS of the production area with an excessive internal moisture generation during the warm season. To ensure set air parameters indoors and considering the internal heat generation as well as the entrance of heat through enclosing structures a method to calculate the required supply air supercooling was developed. It is shown that the additional cooling of the supply air required for the air conditioning can be determined by a simple coefficient which is proportional to the temperature difference of air outside and inside a premise and which 
is defined by the premise constructional properties along with its required air exchange rate and internal heat generation. The thermodynamic analysis of the HPS was carried out taking into account the additional supercooling of the supply air for air conditioning. The purpose of the analysis is to determine air parameters at nodal points of the system and to define conditions under which supply air parameters can be maintained by changing recirculation and fresh air flows. As a result of the study the energy efficiency and HPS operation modes during the warm season were determined depending on the ambient air parameters and the properties of the production area where ventilation and air conditioning are required.

Purpose and tasks. The purpose of the article is the analysis of the ventilation and air conditioning HPS energy efficiency in order to maintain comfort conditions inside the production area with an excessive internal moisture generation during the warm season by using a variable ratio of fresh outside air depending on its parameters.

\section{Description of the ventilation and air conditioning HPS and the ventilation air workflow process}

A schematic drawing of the ventilation and air conditioning HPS with a partial exhaust air recirculation and a variable ratio of fresh outside air is shown in Fig. 1. The following designations are used: $\mathrm{C}_{\mathrm{HP}}-\mathrm{a}$ heat pump condenser; $\mathrm{E}_{\mathrm{HP}}$ - a heat pump evaporator; $\mathrm{C}$ - a compressor; $\mathrm{MC}$ - a mixing chamber; OVAC - an object of ventilation and air conditioning. This HPS was previously designed and studied in work [4]. However, the subject of the current article is to assess operating mode of this HPS not only for ventilation demands but also for air conditioning during the warm season. The system operation principle is as follows: fresh outside air at a temperature $t_{0}$, a moisture content $d_{0}$ and with a mass flow rate $G_{0}$ is supplied to the HP evaporator where it is cooled with a partial water vapour condensation up to a temperature $t_{\mathrm{ev}}$ and a moisture content $d_{\mathrm{ev}}$. The exhaust air from the premise at a temperature $t_{2}$, a moisture content $d_{2}$ and with a mass flow rate $G_{\text {tot }}$ is supplied to the HP condenser where it is heated to a temperature $t_{\text {ex }}$ at the constant moisture content $d_{2}$. Heated exhaust air is then divided into two flows: one flow with a mass flow rate $G_{0}$ is discharged into the environment; the second flow is fed to the mixing chamber where it is mixed with the cooled outside air after the HP evaporator. The resulting air mixture $\left(t_{1}, d_{1}, G_{\text {tot }}\right)$ after the mixing chamber is supplied to the production area for ventilation and air conditioning demands (to compensate the entrance of heat through enclosing structures and internal heat generation). The ventilation air workflow process, which indicates different air conditions inside the studied system, can be presented using the $h-d$ diagram and it is shown in Fig. 2. Point $O$ describes a condition of the ambient air $\left(t_{\mathrm{o}}, h_{\mathrm{o}}\right)[5]$.

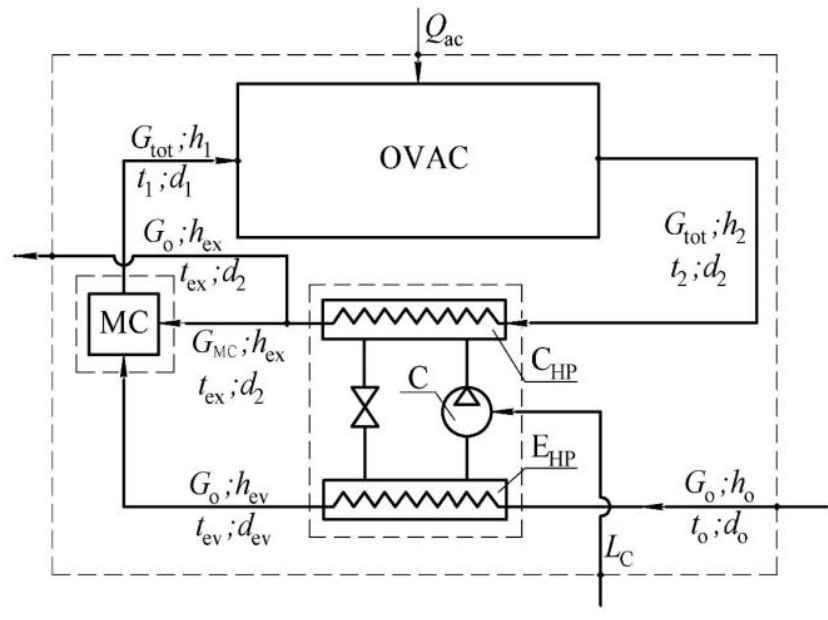

Fig. 1. A general design of the ventilation and air conditioning HPS inside a premise with an excessive internal moisture generation.

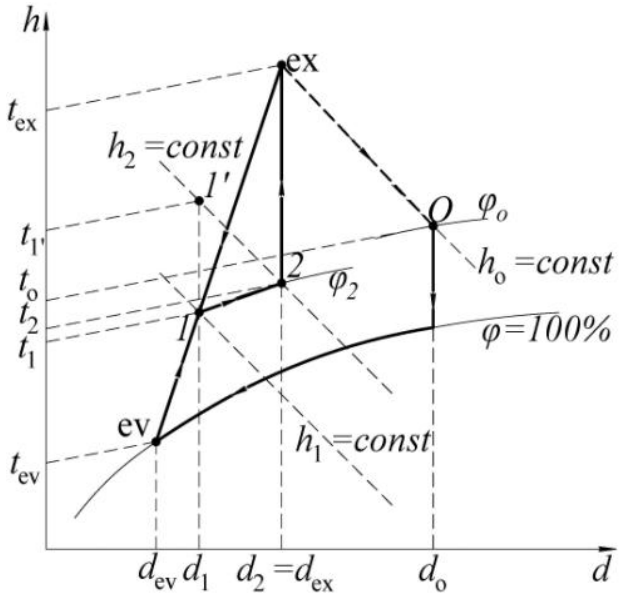

Fig. 2. The ventilation air workflow process inside the studied system presented using the $h-d$ diagram.

Point 2 is set according to the required temperature $t_{2}$ and the relative humidity $\varphi_{2}$ of the air inside the production area. It is determined as provided by [6] depending on the premise technological purpose. Using the $h$ - $d$ diagram $h_{2}$ is defined. According to the building standards [6] the value of additional supply air heating $\Delta t_{\mathrm{v}}$ for the given premise is defined and using the temperature $t_{1^{\prime}}=t_{2}+\Delta t_{\mathrm{v}}$ the point $l^{\prime}$ is obtained on 
the line $h_{2}=$ const. This point corresponds to the supply air state for ventilation demands only. The process $1 '-1$ depicts the additional supply air cooling in order to meet air conditioning demands. Air temperature at point $l$ on the line $d_{1^{\prime}}=$ const can be defined based on the relationship between the temperature difference which corresponds to the additional supply air cooling at the entrance to a premise and the temperature difference of air outside and inside the premise, i.e.

$$
\Delta t=t_{1^{\prime}}-t_{1}=K\left(t_{0}-t_{2}\right)
$$

where $K$ is a proportion coefficient that depends on external and internal entrances of heat.

The exhaust air with parameters at point 2 is heated in the HP condenser to a temperature $t_{\mathrm{ex}}$ at the constant moisture content $d_{2}$. One flow is discharged into the environment and the second flow is mixed with the outside air cooled in the HP evaporator (point ev) creating an air mixture at point $l$ with a moisture content $d_{1^{\prime}}=d_{1}$ and a temperature $t_{1}$ which is then supplied to the production area for ventilation and air conditioning demands. Process 1-2 corresponds to the workflow process of air condition change inside the premise.

\section{Determination of the supply air temperature at the premise entrance}

The relationship between the additional cooling of the supply air to meet air conditioning demands and the temperature difference of air outside and inside a premise can be estimated in the following way

$$
\Delta t=t_{1}-t_{1}=K\left(t_{0}-t_{2}\right),
$$

where $K$-a proportion coefficient that depends on external and internal entrances of heat.

The additional cooling of supply air $\Delta t$ can also be presented as

$$
\Delta t=\Delta t_{1}+\Delta t_{2}
$$

where $\Delta t_{1}, \Delta t_{2},{ }^{\circ} \mathrm{C}$ - additional cooling of supply air to compensate external and internal entrances of heat respectively.

Additional cooling $\Delta t_{1}$ can be written by analogy to the equation (1), and $\Delta t_{2}$ can be expressed from the heat energy demands equation for air conditioning (to compensate internal heat generation). Considering this the equation (2) takes form

$$
\Delta t=K_{1}\left(t_{0}-t_{2}\right)+\frac{Q_{\text {int }}}{G_{\mathrm{tot}} c_{\mathrm{p}}},
$$

where $K_{1}$ - the proportion coefficient which depends on the premise constructional properties and needs to be determined.

Equating expressions (1) and (3) and dividing them by the temperature difference $\left(t_{0}-t_{2}\right)$, the following is obtained

$$
K=K_{1}+K_{2} \text {, }
$$

where $K_{2}=\frac{Q_{\text {int }}}{G_{\text {tot }} c_{\mathrm{p}}\left(t_{0}-t_{2}\right)}$.

In order to determine coefficient $K_{1}$ the next equations to calculate required heat energy demands for ventilation and air conditioning (to compensate external entrance of heat) should be written down

$$
\begin{aligned}
& Q_{\mathrm{v}}=G_{\mathrm{tot}}\left(h_{0}-h_{1}\right), \\
& Q_{\mathrm{ac}}=G_{\mathrm{tot}} c_{\mathrm{p}}\left(t_{1^{\prime}}-t_{1}\right) .
\end{aligned}
$$

From equations (6) and (7) considering previously expressed additional cooling $\Delta t_{1}$ the following can be written

$$
K_{1}=\frac{Q_{\mathrm{ac}}}{Q_{\mathrm{v}}} \frac{\left(h_{0}-h_{1}\right)}{c_{\mathrm{p}}\left(t_{0}-t_{2}\right)} .
$$

On the other hand, the entrance of heat through enclosing structures and heat consumption for ventilation can be defined as:

$$
Q_{\mathrm{ac}}=\bar{K} F\left(t_{0}-t_{2}\right),
$$




$$
Q_{\mathrm{v}}=G_{\mathrm{v}}\left(h_{0}-h_{1}\right),
$$

where $\bar{K}, \mathrm{~W} /\left(\mathrm{m}^{2} \cdot{ }^{\circ} \mathrm{C}\right)$ - an average heat transfer coefficient of production area enclosure structures; $F, \mathrm{~m}^{2}-$ an area of enclosure structures through which heat enters to the production area; $G_{\mathrm{v}}, \mathrm{kg} / \mathrm{s}-$ an air mass flow rate for ventilation system demands.

The air mass flow rate $G_{\mathrm{v}}$ can be calculated depending on a production premise volume $V_{\text {prem }}$ and an air exchange rate $K_{\text {a.ex }}, 1 / \mathrm{h}$, using the relationship

$$
G_{\mathrm{v}}=\rho_{\mathrm{a}} V_{\text {prem }} \frac{K_{\text {a.ex }}}{3600},
$$

where $\rho_{\mathrm{a}}-$ air density.

From equations (9) and (10) considering (11) the expression for $Q_{\mathrm{ac}} / Q_{\mathrm{v}}$ can be defined as

$$
\frac{Q_{\mathrm{ac}}}{Q_{\mathrm{v}}}=\frac{3600 \bar{K} F\left(t_{0}-t_{2}\right)}{\rho_{\mathrm{a}} K_{\text {a.ex }} V_{\text {prem }}\left(h_{0}-h_{1}\right)} .
$$

Then the expression of the proportion coefficient according to the equation (8) and considering (12) assumes the following form

$$
K_{1}=\frac{3600 \bar{K} F}{\rho_{\mathrm{a}} c_{\mathrm{p}} K_{\text {a.ex }} V_{\text {prem }}} .
$$

Thus, the proportion coefficient $K$ in the equation (1) can be predetermined by coefficients $K_{1}$ and $K_{2}$. These coefficients are determined by geometric and thermophysical characteristics of a building and the air exchange rate which is determined by the functional purpose of the air conditioning object (coefficient $K_{1}$ ) as well as by internal heat generation within the building (coefficient $K_{2}$ ). The supply air temperature $t_{1}$ at the entrance to the production area can be derived from the equation (1) respectively.

\section{The thermodynamic analysis of the HPS}

The thermodynamic analysis of the studied system is performed based on the preliminary determination of its thermodynamic state depending on the initial set indoor air parameters and the change of ambient air parameters. The ventilation and air conditioning system state in turn depends on the yet unknown air parameters at system's nodal points. The unknown parameters of this system are the ratio of the fresh outside air flow rate supplied to the HP evaporator, air temperatures after the HP evaporator and condenser, the value of the system's refrigeration efficiency. The corresponding relationships for these parameters can be determined from the equations of thermal and material balances of both individual elements inside the system and the system as a whole. The fresh outside air enthalpy at the outlet of the HP evaporator can be determined from the thermal balance equation of the mixing chamber which has the following expression

$$
G_{0} h_{\mathrm{ev}}+G_{\mathrm{MC}} h_{\mathrm{ex}}=G_{\mathrm{tot}} h_{1}
$$

where $G_{0}, G_{\mathrm{MC}}, G_{\mathrm{tot}}, \mathrm{kg} / \mathrm{s}$ - mass flow rates of the fresh ambient, the heated exhaust and the total air flows; $h_{\mathrm{ev}}, h_{\mathrm{ex}}, h_{1}, \mathrm{~kJ} / \mathrm{kg}_{\text {d.a. }}-$ enthalpies of the corresponding air flows.

After dividing left and right parts of the expression (14) by the value $G_{\text {tot }}$ it can be written

$$
K_{0} h_{\mathrm{ev}}+\left(1-K_{0}\right) h_{\mathrm{ex}}=h_{1},
$$

where $K_{0}$ - the ratio of fresh outside air for ventilation demands.

The enthalpy $h_{\mathrm{ev}}$ which is derived from the equation (15) takes form of

$$
h_{\mathrm{ev}}=\frac{h_{1}-\left(1-K_{0}\right) h_{\mathrm{ex}}}{K_{0}} \text {. }
$$

The fresh outside air moisture content at the outlet of the HP evaporator can be determined from the material balance equation of the moisture content for the whole system which has the following expression

$$
G_{\mathrm{tot}}\left(d_{2}-d_{1}\right)+G_{0} d_{0}=G_{0} d_{2}+G_{0}\left(d_{0}-d_{\mathrm{ev}}\right) .
$$


After dividing left and right parts of the expression (17) by the value $G_{\text {tot }}$ and after a few mathematical transformations the following is obtained

$$
d_{\mathrm{ev}}=d_{0}-\frac{K_{0}\left(d_{0}-d_{2}\right)+\left(d_{2}-d_{1}\right)}{K_{0}} .
$$

The air temperature at the outlet of the HP evaporator, $t_{\mathrm{ev}}$, can be determined using the $h-d$ diagram for moist air at the intersection point of the curve $\varphi=100 \%$ with $h_{\mathrm{ev}}$ or $d_{\mathrm{ev}}$.

The HP energy balance equation can be used to determine the ratio of fresh outside air for ventilation demands

$Q_{\mathrm{c}}=Q_{\mathrm{ev}}+L_{\mathrm{c}}$.

The components of the equation (19) are defined as follows:

the heat flow from the HP condenser

$Q_{\mathrm{c}}=G_{\mathrm{tot}}\left(h_{\mathrm{ex}}-h_{2}\right)$;

the heat flow to the HP evaporator

$Q_{\mathrm{ev}}=G_{0}\left(h_{0}-h_{\mathrm{ev}}\right)$;

external electricity expenses for the HP compressor

$L_{\mathrm{c}}=Q_{\mathrm{ev}} / \varepsilon_{\mathrm{HP}}$,

where $\varepsilon_{\mathrm{HP}}$ - the HP refrigeration efficiency.

After a few mathematical transformations, the expression to determine the ratio of fresh outside air for ventilation demands takes form of

$$
K_{0}=\frac{h_{\mathrm{ex}}-h_{2}}{h_{0}-h_{\mathrm{ev}}} \frac{\varepsilon_{\mathrm{HP}}}{\varepsilon_{\mathrm{HP}}+1} .
$$

The operation efficiency of a HP, which works as a refrigeration machine in the air conditioning mode, in this case can be estimated by the value of the HP refrigeration efficiency

$$
\varepsilon_{\mathrm{HP}}=\frac{1}{\frac{273+t_{\mathrm{ex}}+\Delta t_{\mathrm{c}}}{273+t_{\mathrm{ev}}-\Delta t_{\mathrm{ev}}}-1},
$$

where $t_{\mathrm{ev}}$ - the fresh outside air temperature at the outlet of the HP evaporator, ${ }^{\circ} \mathrm{C} ; t_{\mathrm{ex}}-$ the exhaust air temperature at the outlet of the HP condenser, ${ }^{\circ} \mathrm{C} ; \Delta t_{\mathrm{ev}}$ - the temperature difference between the outside air flow and the refrigerant at the outlet of the HP evaporator, ${ }^{\circ} \mathrm{C} ; \Delta t_{\mathrm{c}}$ - the temperature difference between the refrigerant and the exhaust air flow at the outlet of the HP condenser, ${ }^{\circ} \mathrm{C}$. Numerical values of temperature differences in the condenser and the evaporator for an air-to-air HP type are given in the literature. According to [7] it is possible to assume that $\Delta t_{\mathrm{c}}=\Delta t_{\mathrm{ev}}=10^{\circ} \mathrm{C}$ for the HP condenser and the HP evaporator respectively.

The HP refrigeration efficiency in this study is estimated for ideal reversed Carnot cycle which considers only heat irreversibilities inside HP evaporator and condenser due to the existing temperature differences $\Delta t_{\mathrm{ev}}$ and $\Delta t_{\mathrm{c}}$. Real processes which a working medium undergoes inside a HP are not reviewed for several reasons. First, since a HP operates as a refrigeration machine the temperature difference between its surfaces and the environment is less during the warm season comparing to winter period when a HP works to provide heating demands. With lower heat losses the efficiency of HP operation increases. Second, this assumption was made to compare results with the previous study [4] which was also carried out for ideal refrigeration cycle.

The exhaust air enthalpy at the outlet of the HP condenser can be determined from the thermal balance equation of the whole system which has the following expression including the entrance of heat through enclosing structures

$$
G_{0} h_{0}+L_{\mathrm{c}}+Q_{\mathrm{ac}}=G_{0} h_{\mathrm{ex}} .
$$

After dividing left and right parts of the expression (25) by the value $G_{\text {tot }}$ and considering equation (1) in $Q_{\mathrm{ac}}$, the following can be obtained 


$$
h_{\mathrm{ex}}=h_{0}+\left(h_{0}-h_{\mathrm{ev}}\right) \frac{1}{\varepsilon_{\mathrm{HP}}}+\frac{c_{\mathrm{p}} K\left(t_{0}-t_{2}\right)}{K_{0}} .
$$

The air temperature at the outlet of the HP condenser, $t_{\mathrm{ex}}$, can be determined using the $h$ - $d$ diagram for moist air at the intersection point of $h_{\mathrm{ex}}$ with the moisture content indoors $d_{2}$. Enthalpy $h_{1}$ can be determined by the following formula for a moist air with enough accuracy [5]

$$
h_{1}=1.005 t_{1}+\left(2500+1.8 t_{1}\right) d_{1} \text {. }
$$

The HP refrigeration efficiency, as well as the HP coefficient of performance (COP), only depends on the operating conditions of the HP itself, i.e. the temperature level of heat transfer processes in the HP evaporator and condenser. Therefore, to characterise the efficiency of the whole HPS it is more appropriate to use a complex value (system refrigeration efficiency), which can be presented in the following way

$$
\varepsilon_{\mathrm{S}}=\frac{Q_{\text {cold }}}{L_{\mathrm{c}}},
$$

where $Q_{\text {cold }}, \mathrm{kW}$ - the refrigeration capacity at the entrance to the premise.

It is determined as

$$
Q_{\text {cold }}=G_{\text {tot }}\left(h_{0}-h_{1}\right) \text {. }
$$

Considering equations (21), (22) and (29), the expression (28) can be written as follows

$$
\varepsilon_{\mathrm{S}}=\frac{\varepsilon_{\mathrm{HP}}\left(h_{0}-h_{1}\right)}{K_{0}\left(h_{0}-h_{\mathrm{ev}}\right)} .
$$

\section{Numerical analysis of the HPS for ventilation and air conditioning}

Numerical analysis of the HPS for ventilation and air conditioning is done for a typical production area with an excessive internal moisture generation. Roshen Confectionery production workshop in Kyiv region was selected as the prototype [8]. In order to ensure comfortable working conditions the following indoor air parameters were set in the workshop [6]: the premise temperature $t_{2}=18{ }^{\circ} \mathrm{C}$; the premise relative humidity $\varphi_{2}=50 \%$; the additional heating of the supply air for the ventilation purposes $\Delta t_{\mathrm{v}}=3{ }^{\circ} \mathrm{C}$.

Under the given conditions the air moisture content at the inlet and outlet of the premise was determined. These are the points 1 and 2 respectively on the diagram in Fig. $2: d_{1}=5.3 \mathrm{~g} / \mathrm{kg}_{\text {d.a. }}$ and $d_{2}=6.5$ $\mathrm{g} / \mathrm{kg}_{\text {d.a. }}$. Numerical analysis using the equations (16), (20), (23), (24), (26), (27) and (30) and the method of successive approximations allows to estimate the influence of changes in the environment temperature and relative humidity and the characteristics of the ventilation and air conditioning object on the system parameters (air temperatures at the outlet of the HP evaporator and condenser (Fig. 3), the ratio of fresh outside air (Fig. 4), the HP refrigeration efficiency (Fig. 5)) and the thermodynamic efficiency of the ventilation and air conditioning system (Fig. 5). The chosen calculation method of analysing HPS in its different conditions consists of iteration cycles in the whole range of atmospheric air parameters and with different building characteristics. Iterations complete when the condition of relative deviation is achieved. In this case we consider two parameters $\left(h_{\mathrm{ev}}\right.$ and $K_{0}$ ) which should have a difference between their values after and before an iteration cycle not exceeding $0.5 \%$ for $K_{0}$ and $0.06 \%$ for $h_{\mathrm{ev}}$.

When choosing the value $K$, the following has been assumed. According to the equation (4) and considering (13) for the selected production premise it was calculated that $K=0.23$ (a proportion coefficient depending on external and internal entrances of heat). The obtained value is correct since ventilation expenses can be several times higher than the corresponding entrance of heat for industrial and public buildings [9]. Therefore, the following values of this coefficient were considered $K=0.1 ; 0.2 ; 0.3 ; 0.4 ; 0.5$.

Fig. 3, a-b shows graphical relationships between air flow temperatures at the outlet of the HP condenser and evaporator, the environment temperature and relative humidity and different values of $K\left(t_{\mathrm{ex}}\right.$, $t_{\mathrm{ev}}=f\left(t_{0}, \varphi_{0}, K\right)$ ). The case when $K=0$ (plots 11 and 12) corresponds to the absence of air conditioning which was described in work [4]. Temperature $t_{\mathrm{ex}}$ is limited by a critical value at which normal operation of the HP condenser is still possible. It is seen that application conditions of this system deteriorate with increasing environment relative humidity. Thus, the application range of this system is from $t_{0}=25{ }^{\circ} \mathrm{C}\left(\varphi_{0}=\right.$ $80 \%)$ to $t_{0}=33{ }^{\circ} \mathrm{C}\left(\varphi_{0}=40 \%\right)$. This suggests that this HPS is suitable for application in countries with 
temperate continental climate. Temperatures $t_{\mathrm{ev}}$ at $t_{0}>25{ }^{\circ} \mathrm{C}$ almost do not depend on environment relative humidity $\varphi_{0}$ and temperature $t_{0}$ and average $4{ }^{\circ} \mathrm{C}$. However, the difference between them is greater the lower the values of $\varphi_{0}$ and $t_{0}$ are.

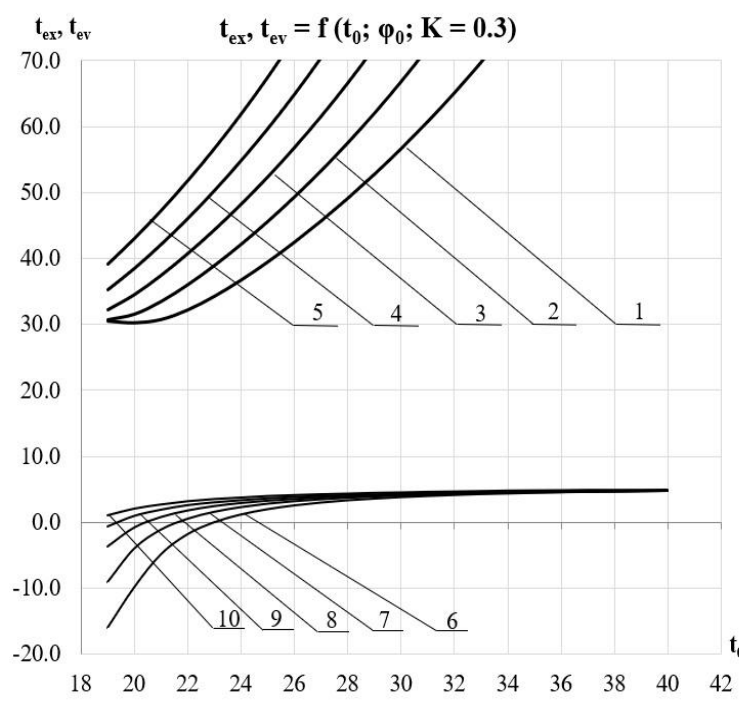

a)

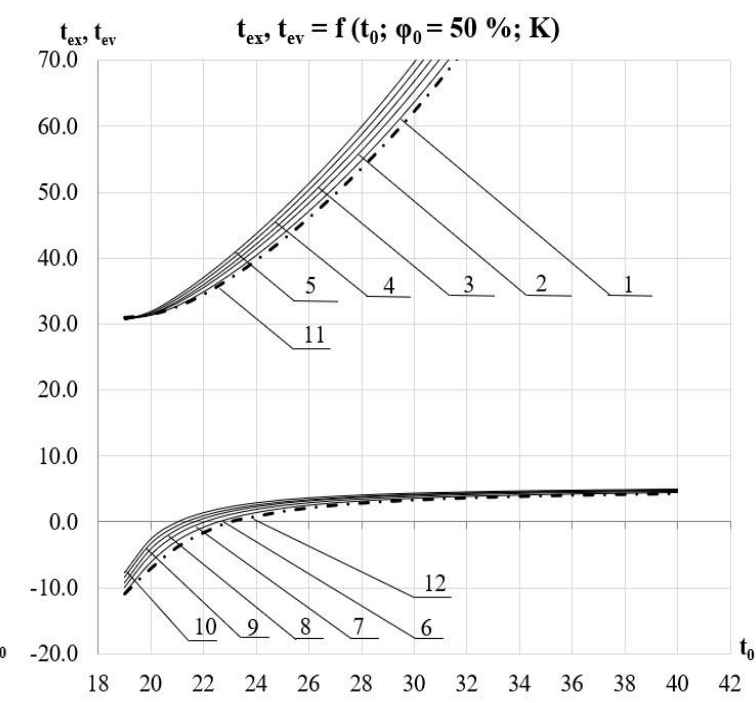

b)

Fig. 3. Graphical relationships between air temperatures at the outlet of the HP condenser and evaporator, the environment temperature and relative humidity and the coefficient $K$ : a) $K=0,3 ; t_{\mathrm{ex}}: 1-\varphi_{0}=40 \% ; 2-50 \% ; 3-60 \%$; $\left.4-70 \% ; 5-80 \% ; t_{\mathrm{ev}}: 6-\varphi_{0}=40 \% ; 7-50 \% ; 8-60 \% ; 9-70 \% ; 10-80 \% ; \mathrm{b}\right) \varphi_{0}=50 \% ; t_{\mathrm{ex}}: 1-K=0.1 ; 2-0.2$; $3-0.3 ; 4-0.4 ; 5-0.5 ; 11-0 ; t_{\mathrm{ev}}: 6-K=0.1 ; 7-0.2 ; 8-0.3 ; 9-0.4 ; 10-0.5 ; 12-0$.

An important characteristic of this system is the fresh outside air flow rate ratio at the entrance to the system, $K_{0}$, which is supplied to the HP evaporator. The corresponding calculated data for the variable fresh air ratio obtained by the equation (23) are shown in Fig. 4. Plot 6 shows HPS that maintains only ventilation demands [4]. As can be seen from the plots, the variable ratio of fresh outside air to fulfill the requirement of maintaining set comfortable air parameters in the premise must vary depending on both the temperature $t_{0}$ and the relative humidity $\varphi_{0}$ of the ambient air. At a constant temperature $t_{0}$ the need for fresh air increases with the increase of both relative humidity $\varphi_{0}$ and the coefficient $K$, i.e. entrance of heat to the premise. As $\varphi_{0}$ increases, the enthalpy $h_{0}$ increases as well. This leads to an increase of the exhaust air temperature $t_{\mathrm{ex}}$ at the outlet of the HP condenser. As a result, a larger ratio of fresh air at higher relative humidity $\varphi_{0}$ is supplied to the mixing chamber. Therefore, the design of HPS for ventilation and air conditioning should be done with the variable fresh air supply, because otherwise the system will not be able to provide required conditions inside the premise depending on changes in environment parameters.
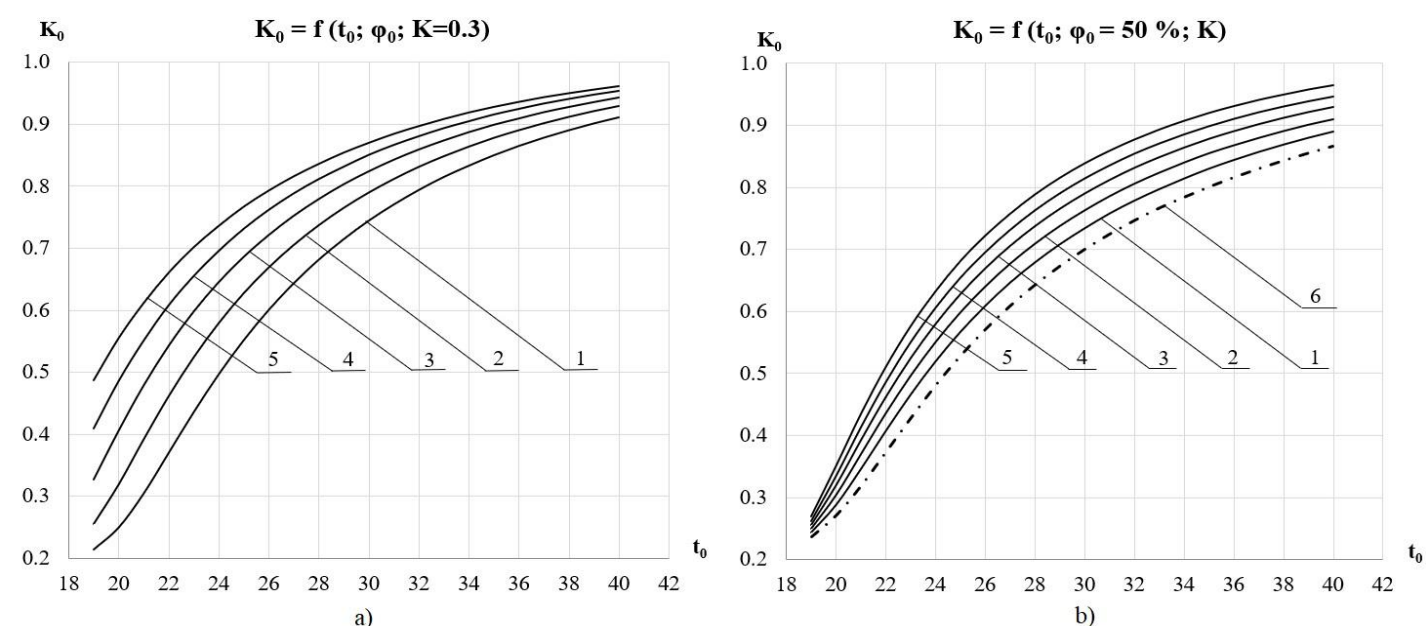

Fig. 4. Graphical relationships between the variable ratio of fresh outside air, the environment parameters and the coefficient $K$ : a) $K=0.3 ; 1-5-\varphi_{0}=40-80 \%$; b) $\varphi_{0}=50 \% ; 1-5-K=0.1-0.5 ; 6-K=0$. 
Based on the numerical analysis of equations (24) and (30) graphical relationships between HP and HPS refrigeration efficiencies, the environment temperature and relative humidity and different values of the coefficient $K$ were obtained $\left(\varepsilon_{\mathrm{HP}}, \varepsilon_{\mathrm{S}}=f\left(t_{0}, \varphi_{0}, K\right)\right.$ ) (Fig. 5, a-b). Again plots 11 and 12 are for $K=0$. The HP refrigeration efficiency is characterised by high values in the range of moderate temperatures $t_{0}=20-30{ }^{\circ} \mathrm{C}$.

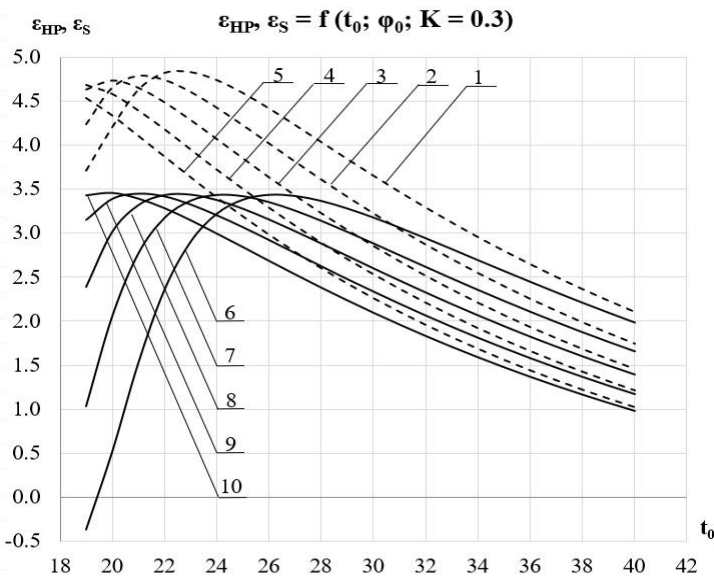

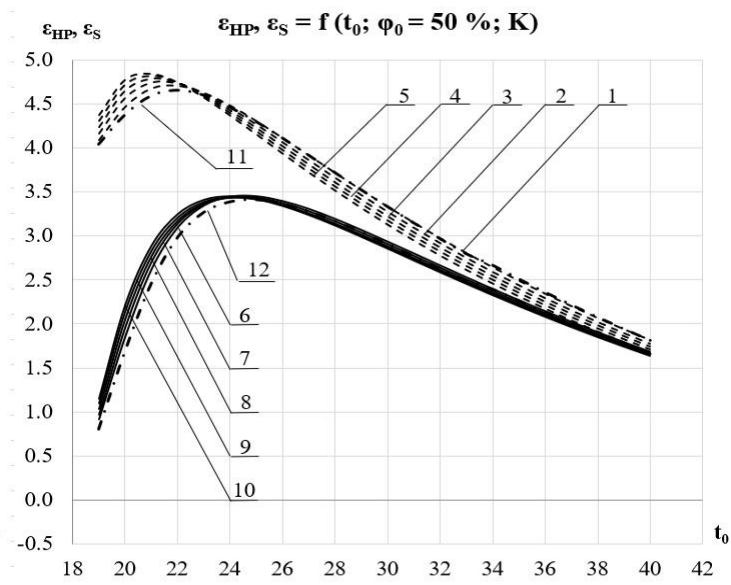

Fig.5. Graphical relationships between HP and HPS refrigeration efficiencies, the environment parameters and the coefficient $K$ : a) $K=0.3 ; \varepsilon_{\mathrm{HP}}: 1-5-\varphi_{0}=40-80 \% ; \varepsilon_{\mathrm{S}}: 6-10-\varphi_{0}=40-80 \%$; b) $\varphi_{0}=50 \% ; \varepsilon_{\mathrm{HP}}: 1-5-$

$$
K=0.1-0.5 ; 11-K=0 ; \varepsilon_{\mathrm{S}}: 6-10-K=0.1-0.5 ; 12-K=0 .
$$

It decreases significantly with the further growth of $t_{0}$ as well as with the increasing relative humidity $\varphi_{0}$. Plots show that the HPS refrigeration efficiency reaches highest values also in the zone of low environment temperatures and largely depends on the relative humidity of the outside air. Values of HP and HPS refrigeration efficiencies do not depend much on the premise properties, i.e. the coefficient $K$, in the entire temperature range $t_{0}$. In general, the studied HPS can have high energy efficiency when it is used in temperate latitudes. It should also be noted that this system, which is designed for operation during the warm season (cooling and drying of fresh outside air), has its limitations. Fig. 6 shows two air workflow processes which indicate different air conditions inside the ventilation and air heating HPS (a) and the ventilation and air conditioning HPS (b). The first process was obtained as a result of the HPS analysis for this object during the cold season. Results of this analysis are presented in [10]. According to them, depending on the relative humidity $\varphi_{0}$, there exists a critical outside air temperature $t_{0}$, above which the HPS in the operating mode a) will not be able to provide comfortable conditions in the premise due to the incoming excessive moisture from the environment.

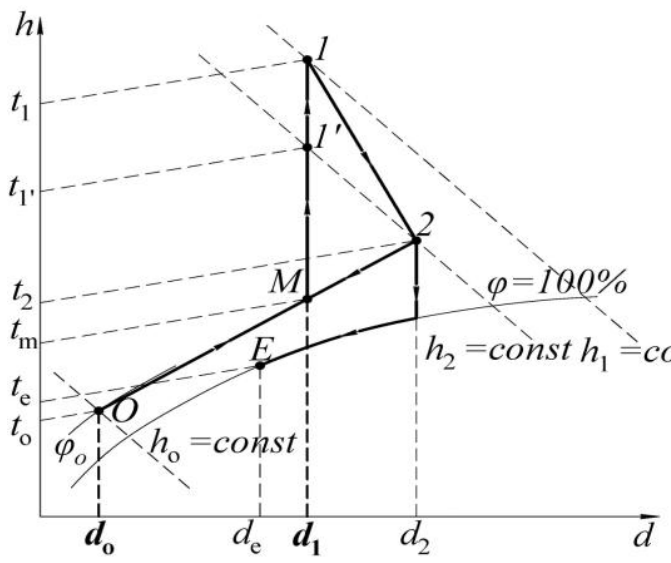

a)

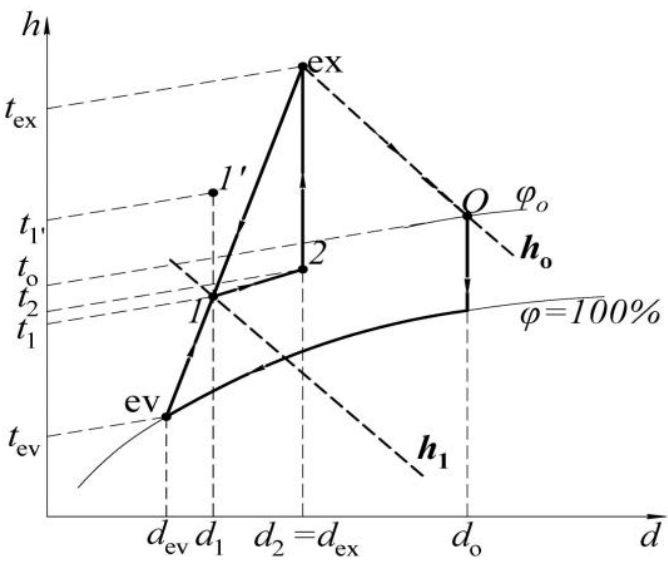

b)

Fig.6. Air workflow processes which indicate different air conditions inside the ventilation and air heating HPS (a) and the ventilation and air conditioning HPS (b). 
This situation occurs when the outside air moisture content exceeds the set moisture content of the supply air at point 1 , i.e. $d_{0}>d_{1}=5.3 \mathrm{~g} / \mathrm{kg}_{\text {d.a }}$ (Fig. 6 , a). In case of exceeding the outside air temperature limit values a fundamental change of the system is required with its following transition to the air conditioning mode in which the supply air is cooled and drained. The result of this problem solution is the given HPS for ventilation and air conditioning, the working process of which is shown in Fig. 2 and Fig. 6, b. According to Fig. 6, b the boundary condition for this system application will be the situation when the outside air enthalpy becomes lower than the enthalpy of the air mixture at point 1 , i.e. $h_{0}<h_{1}=34.7 \mathrm{~kJ} / \mathrm{kg}_{\text {d.a }}$ (Fig. $\left.6, \mathrm{~b}\right)$.

\section{Conclusions}

Efficiency of the studied system comparing to one in work [4] increased due to the presence of air conditioning. This effect occurs because of partial utilisation of generated cold within the system. However, the benefit is only in a range of relatively low outside air temperatures. The higher demands for air conditioning are, the faster air temperatures after HP condenser will reach critical values at which the work of HPS is not recommended.

It is shown that the required additional cooling of the supply air at the entrance to the premise for air conditioning demands can be determined by a simple coefficient $K$ which is proportional to the temperature difference of air outside and inside a premise and which is defined by the premise constructional properties along with its required air exchange rate, determined by the functional purpose of the object of ventilation and air conditioning, as well as by the premise internal heat generation. The studied system of ventilation and air conditioning in premises with an excessive internal moisture generation can provide maintenance of the required conditions indoors during the warm season only up to moderate values of outside air parameters, further increase of which is limited by the maximum temperature of the exhaust air after the HP condenser.

The studied system of temperature and humidity maintenance has the highest energy efficiency in the zone of relatively low environment temperatures and largely depends on the relative humidity of the outside air. This suggests that this HPS is suitable for application in countries with temperate continental climate. The results of the study will be used for further scientific work on the improvement of existing heating, ventilation and air conditioning heat pump systems.

\section{REFERENCES}

1 Ukraine's new energy strategy until 2035: "security, energy efficiency, competitiveness". Kyiv, Ministry of Energy and Coal Industry of Ukraine, 2017, 53 p.

2 Khrustaliov B. M. Heat supply and ventilation. Moscow, ASV, 2007, 784 p.

3 Yu-Yuan Hsieh, et al. A study of heat-pump fresh air exchanger. Applied Thermal Engineering, 2018, Vol. 132, No. 5, pp. 708-718.

4 Bezrodny M., et al. Efficiency of heat pump systems of air conditioning for removing excessive moisture. Archives of Thermodynamics, 2019, Vol. 40, No. 2, pp. 151-165. DOI: 10.24425/ather.2019.129546

5 Bozhenko M. F. Heat sources and heat consumers. Kyiv, NTUU KPI "Politehnika", 2004, 192 p.

6 State Building Standards of Ukraine DBN B.2.5-67: 2013, "Heating, ventilation and air conditioning”. Kyiv, Ministry of Regional Development, Construction and Housing of Ukraine, 2013, 149 p.

7 Morozjuk T. V. The theory of chillers and heat pumps. Odesa, Studija "Negociant", 2006, 712 p.

8 Bezrodny M., et al. Thermodynamic analysis of the heat pump ventilation system for support of comfort conditions in industrial premises with release of moisture. NTU "HPI”, 2018, No. 13, pp. 77-82. DOI: 10.20998/2078774X.2018.13.14

9 Bezrodny M. K. Thermodynamic and energy efficiency of heat pump heat supply circuits: monograph. Kyiv, NTUU KPI "Politehnika", 2016, 272 p.

10 Bezrodny M., Misiura T. The heat pump system for air heating and ventilation inside the production area with an excessive internal moisture generation. KPI Science News, 2020, No. 2, pp. 7-16. DOI: 10.20535/kpi-sn.2020.2.205111

Article accepted for publication 07.08.2020 